African Crop Science Journal by African Crop Science Society is licensed under a Creative Commons Attribution 3.0 Uganda License. Based on a work at www.ajol.info/ and www.bioline.org.br/cs DOI: https://dx.doi.org/10.4314/acsj.v27i2.9

\title{
EFFECTIVENESS OF PRUNING AND WAXING IN REDUCING POSTHARVEST PHYSIOLOGICAL DETERIORATION IN UGANDA LOCAL CASSAVA VARIETIES
}

\author{
E. NUWAMANYA ${ }^{1}$, S. ACHENG ${ }^{1,4}$, P. VUZI ${ }^{4}$, H. MUYINZA ${ }^{3}$, M. MATOVU ${ }^{3}$, E. ATWIJUKIRE ${ }^{1}$, \\ G. MENYA ${ }^{3}$, K. WANDA ${ }^{2}$, E. NYAKAISIKI ${ }^{5}$ and B.A. ADEBAYO ${ }^{2}$ \\ ${ }^{1}$ Cassava Programme, National Crops Resources Research Institute (NaCRRI), P. O. Box 7084, \\ Kampala, Uganda \\ ${ }^{2}$ Regional Hub for Eastern Africa, International Institute of Tropical Agriculture (IITA), 25 Light \\ Industrial Area, Mikocheni B, Dar es Salaam, Tanzania \\ ${ }^{3}$ Food Biosciences Programme, National Agricultural Research Laboratories (NARL), P. O. Box, \\ 7065, Kampala, Uganda \\ ${ }^{4}$ Department of Biochemistry and Sports Science, College of Natural Sciences, Makerere University, \\ P. O. Box 7062, Kampala, Uganda \\ ${ }^{5}$ Department of Food Processing Technology, Faculty of Science, P. O. Box 1, Kyambogo, Uganda
} Corresponding author: nuwamanyaephraim@gmail.com

(Received 12 June 2018; accepted 20 May 2019)

\begin{abstract}
Cassava (Manihot esculenta Crantz) roots in the fresh form, are susceptible to postharvest physiological deterioration (PPD), thus reducing their economic value and farmer benefits. The objective of this study was to evaluate the effectiveness of pruning and waxing on fresh root storability among cassava varieties in Uganda. Sixteen cassava plants per variety (TME 14, NASE 14, Nyaraboke, Kirimumpale, and Bukalasa) were pruned seven days before harvest, leaving the rest as unpruned controls. After harvest, roots were divided into two portions and one portion was waxed using food grade wax. Pruning alone reduced PPD of stored roots by $23 \%$ at day 14 of storage; and by $19 \%$ at day 28 compared with the control. Pruning as a treatment resulted into increased sugar content, ranging 9$30 \%)$, and significant $(\mathrm{P}<0.05)$ losses in starch yield. Pruning combined with waxing, resulted in a reduction of up to $43 \%$ in PPD by day 14, and up to 67 at day 28 . Reduction in carbohydrate (starch) was not significant $(\mathrm{P}>0.05)$ under the pruning and waxing treatment, which had minor effects on stored root composition. The results indicate that pruning is appropriate for the short-term storage of fresh cassava roots for up to 14 days. Waxing, combined with pruning, is suitable for longer term storage up to 28 days under Uganda conditions.
\end{abstract}

Key Words: Carbohydrate, Manihot esculenta, starch, storage 
Les racines de manioc (Manihot esculenta Crantz) à l'état frais sont sensibles à la détérioration physiologique après la récolte, réduisant ainsi leur valeur économique et les avantages pour les agriculteurs. L'objectif de cette étude était d'évaluer l'efficacité d'élaguer et de cirer sur la capacité de stockage des racines fraîches parmi les variétés de manioc en Ouganda. Seize plants de manioc par variété (TME 14, NASE 14, Nyaraboke, Kirimumpale et Bukalasa) ont été élagués sept jours avant la récolte, les autres étant des témoins non élagués. Après la récolte, les racines ont été divisées en deux parties et une partie a été cirée avec de la cire de qualité alimentaire. L'élagage seul réduisait la PPD des racines stockées de $23 \%$ au 14e jour de stockage; et de $19 \%$ au 28e jour comparé au témoin. L'élagage en tant que traitement a entraîné une augmentation de la teneur en sucre (comprise entre 9 et 30\%) et une perte significative $(\mathrm{P}<0,05)$ du rendement en amidon. La combinaison d'élaguer et de cirer a entraîné une réduction de la PPD de $43 \%$ au 14e jour et de 67 ans au 28e jour. La réduction de la teneur en glucides (amidon) n'était pas significative $(\mathrm{P}>0,05)$ dans le cadre des traitements d' élaguer et de cirer a eu des effets mineurs sur la composition des racines stockées. Les résultats indiquent que l'élaguage convient au stockage à court terme de racines de manioc fraîches pendant 14 jours au maximum. La combinaison d' élaguer et de cirer convient au stockage à long terme jusqu'à 28 jours dans les conditions ougandaises.

Mots Clés: glucides, Manihot esculenta, amidon, stockage

\section{INTRODUCTION}

Postharvest losses are major factors contributing to food insecurity and significant monetary losses among cassava (Manihot esculenta) farmers, especially in sub Saharan Africa (SSA) (Abass et al., 2014). Cassava roots have high moisture contents and are amenable to microbial attack; which further increases their perishability, in addition to variety specific genetic predispositions to perishability. In response to such problems, traditional efforts and practices have been employed to reduce the losses due to cassava perishability in SSA. However, most of these practices increase production costs; restrict the crops to a small market share, and only address issues related subsistence forms of farming (Nasser and Ortiz, 2010).

Therefore, efforts to reduce such losses are required if cassava is to move to extended markets, including industrial application. This will greatly contribute to improved food security in areas where cassava is a staple crop. Reduction of such losses also has a positive impact on economic security of value chain actors engaged in storage and processing of cassava roots and their production.

The rapid perishability and postharvest losses of cassava roots result from their high moisture content (70-80\%), large unit sizes (0.5-5 $\mathrm{kg}^{-1}$ root), soft texture, and high respiration rates (Atanda et al., 2011). Although there have been efforts to improve some of these characteristics through breeding (Zidenga et al., 2012), such efforts have not provided a wholesome variety that would address all loss factors along the value chain. Thus, there is need to control post-harvest cassava losses through agronomic practices and postharvest management procedures. Some of the common procedures include pruning (leaf defoliation) before harvest and the covering of harvested cassava roots with molten wax (waxing) (Van Oirschot et al., 2000; Zidenga et al., 2012). These procedures (waxing and pruning) are critical in improving the physiological state of the roots, and preventing mechanical injury afterwards.

Pruning in particular interrupts the physiological processes in the root, leading to delay of the onset of postharvest physiological 
deterioration (PPD), and hence, improves its storage properties (Van Oirschot et al., 2000). However, this has been alleged to affect the eating quality of the roots, thus affecting the final product (Bhat et al., 2012). Asaoka et al. (1993) reported that pruning may affect the starch content of cassava roots and, henceforth affect their utilisation. For consumers in Uganda, such procedure therefore, needs to be evaluated as it may affect the acceptability of fresh cassava roots by consumers.

Waxing of fresh cassava roots on the other hand, has been shown to reduce spoilage in fresh roots by up to $50 \%$, within the first 14 days after harvest (Zidenga et al., 2012). Waxed roots after harvesting can be transported more easily over longer periods of time, and hence, can be sold as a premium product in high-end markets such as urban areas and supermarkets, or for export (Wanda et al., 2014). Application of wax could be used to reduce spoilage even on an industrial scale (Simonyan, 2014). Nonetheless, Africa has not fully exploited the waxing technology as a shelf-life improving technology for root and tuber crops (Wanda et al., 2014). In addition, no specific studies have highlighted the effect of waxing on pruned cassava roots. However, it is hypothesized that an additive effect may be achieved by waxing pruned roots and may achieve more storage time and higher root quality.

The purpose of this study, therefore, was to determine the effect of pruning and waxing as a treatment on the biochemical properties and storability of market-preferred varieties of cassava for use in fresh forms in Uganda.

\section{MATERIALS AND METHODS}

Field establishment. Cassava farmers were identified in the cassava growing regions of Kabarole, Kiryandongo and Kyenjonjo in Uganda. The selected areas form the major sources of fresh cassava that is sold in urban areas, especially Kampala. Three cassava farmers were identified in each of the districts. The farmers were provided with clean planting materials of the five varieties (TME 14, NASE 14, Nyaraboke, Kirimumpale, and Bukalasa). These varieties were mostly sold in the urban centres in the fresh form, and were used for home consumption (Wanda et al., 2016). They also have low hydrogen cyanide contents (50 ppm fresh weight basis) (Kawuki et al., 2011) and were considered as sweet varieties.

The experimental plots were set up in the selected farmer fields in a randomised complete block design, with a block size of $6 \times 6$ plants in each of the fields. The plants were allowed to grow up to 12 months, after which the roots were harvested while taking care not to harm the roots before being evaluated for PPD and related parameters.

Sample selection, pruning and harvesting. At 12 MAP, twenty plants of each variety were selected. The confounding effect of cassava brown streak was avoided by selecting plants and roots with no visible symptoms of the disease. Root necrosis during CBSD infestation leads to browning, which would complicate the characterisation of PPD in the root. Sixteen plants, out of the selected twenty, were pruned by removal of the leaves seven days before harvesting; according to procedures established by Van Oirschot et al. (2000). After seven days, all the selected plants (16 pruned and 4 not pruned) were uprooted manually, with care to avoid damaging the roots during and after harvesting.

Root treatment. From the harvested plants, 15 straight, even and undamaged roots of unpruned plants (Control or CTR) and 30 straight, even and undamaged roots from the 16 pruned plants (PR) of each variety were selected. The selection of the roots was based on their suitability for waxing (even root surface, long peduncle, and small size of $<10$ $\mathrm{cm}$ diameter and without physical damage) (Wanda et al., 2016). 
The roots were cleaned, washed with potable water and a soft bristled brush was used to remove adhering soil during the cleaning. The cleaned roots were allowed to drain for $10 \mathrm{~min}$, followed by removal of excess water by wiping of the roots using a clean cloth towel.

Drying of the roots was achieved by placing them on a dry surface at room temperature $\left(24-27^{\circ} \mathrm{C}\right)$, and turning them over at 30 -minute intervals for even drying. Dried and clean cassava roots were dipped in a solution containing $1 \%$ of the fungicide (Ridomil Gold ${ }^{\circledR}$ Syngenta) mixed with $0.5 \%$ of the surfactant (Silwet Gold® Syngenta) for about $30 \mathrm{sec}$. The combination of the fungicide and surfactant is an affordable food grade combination that is used in the food industry (Kralova and Sjöblom, 2009). The disinfected roots were dried for about $20 \mathrm{~min}$ in a cool and open area, and divided into two groups (15 roots each). One group remained ready for storage (PR) and the second was waxed (PRWX) by being dipped in molten food grade wax $\left(140{ }^{\circ} \mathrm{C}\right)$ for about $2-5 \mathrm{sec}$. Pruning and waxing were taken as a single treatment combination. The treated (PR and PRWX) and untreated (CTR) roots were stored in ambient conditions for 28 days. The whole experimental process (pruning and waxing) was repeated during the wet seasons (SeptOct 2015 and March-April 2016) when the soil was soft.

Biochemical assessment. At weekly intervals (day 7, 14, 21 and 28), the stored roots were evaluated for postharvest physiological deterioration (PPD), and root composition. The roots were screened for PPD according to the method described by Morante et al. (2010), involving the scoring of the roots depending on the root area affected by PPD. The PPD was expressed as the percentage of affected portion/area of the root, in relation to the whole portion of the root at the different days of sampling.
Dry matter, starch content, amylose and reducing sugar contents of the roots were determined using methods described by Benesi et al. (2008). Total cyanide was determined according to the method by Bradbury et al. (1991). Total crude protein content was determined using a micro Kjeldahl technique (AACC Method 46-13.01); and total dietary fiber (TDF) was quantified by the enzyme gravimetric method (AOAC 985.29)

Statistical analysis. The data obtained were analysed using GenStat Discovery edition 4.1. To test the significance of variation due to the treatments, a two way analysis of variance was conducted with treatment days as a fixed effect and treatments as variables. Treatment means were separated using Fisher's Least Significant Difference (LSD) test at 5\% probability level. Correlation analyses were performed across different treatments.

\section{RESULTS AND DISCUSSION}

\section{Postharvest physiological deterioration}

(PPD). The results for the changes in PPD and, hence, the shelf life of cassava under different treatments are presented in Table 1. In control samples (samples that were not pruned or waxed) of the local varieties (Nyaraboke, Kirimumpale and Bukalasa), PPD increased to at least $49 \%$ within the first 14 days of storage; and reached $>85 \%$ by day 28 (Table 1). On the other hand, PPD of the improved varieties was lower; reaching $28.40 \%$ for TME14 and $25.67 \%$ for NASE 14 on day 14 after harvesting. Local variety, Kirimumpale, had the highest PPD score (50.55); followed by Nyaraboke and Bukalasa in the control, as early as day 14 .

The low values of PPD observed in improved varieties point to deliberate actions by the breeding programme to select for varieties with low PPD, and hence, higher shelf life (Tumuhimbise et al., 2014). Such varieties are grown in the country for fresh 
TABLE 1. Change in Postharvest Physiological Deterioration (PPD) (percentage \pm SE) during storage of treated roots from different cassava varieties grown in Uganda

\begin{tabular}{|c|c|c|c|c|c|c|}
\hline \multirow[t]{2}{*}{ Variety } & \multirow[t]{2}{*}{ Treatment } & \multicolumn{5}{|c|}{ Storage period (days) } \\
\hline & & 0 & 7 & 14 & 21 & 28 \\
\hline \multirow[t]{3}{*}{ TME 14} & CTR & 0.00 & $5.45 \pm 0.78$ & $28.40 \pm 2.17$ & $66.23 \pm 0.42$ & $84.40 \pm 1.21$ \\
\hline & PR & 0.00 & $5.30 \pm 1.27$ & $17.97 \pm 0.99$ & $55.95 \pm 0.79$ & $81.25 \pm 0.25$ \\
\hline & PRWX & 0.00 & $3.15 \pm 1.34$ & $4.70 \pm 1.49$ & $16.62 \pm 2.35$ & $18.29 \pm 2.91$ \\
\hline \multirow[t]{3}{*}{ NASE 14} & CTR & 0.00 & $10.3 \pm 0.85$ & $25.67 \pm 0.53$ & $77.18 \pm 3.93$ & $84.72 \pm 2.98$ \\
\hline & PR & 0.00 & $9.81 \pm 2.26$ & $20.17 \pm 1.85$ & $59.14 \pm 0.29$ & $84.99 \pm 1.71$ \\
\hline & PRWX & 0.00 & $4.70 \pm 0.28$ & $7.75 \pm 1.39$ & $16.29 \pm 4.10$ & $28.55 \pm 4.03$ \\
\hline \multirow[t]{3}{*}{ Nyaraboke } & CTR & 0.00 & $36.7 \pm 5.52$ & $49.44 \pm 5.01$ & $71.24 \pm 1.15$ & $88.39 \pm 1.23$ \\
\hline & PR & 0.00 & $6.50 \pm 1.13$ & $16.66 \pm 1.86$ & $53.59 \pm 6.09$ & $76.59 \pm 1.03$ \\
\hline & PRWX & 0.00 & $4.20 \pm 0.00$ & $6.41 \pm 0.76$ & $14.30 \pm 5.21$ & $21.25 \pm 1.92$ \\
\hline \multirow[t]{3}{*}{ Kirimumpale } & CTR & 0.00 & $31.45 \pm 2.75$ & $50.55 \pm 8.87$ & $83.76 \pm 4.99$ & $93.21 \pm 1.46$ \\
\hline & PR & 0.00 & $18.75 \pm 0.92$ & $29.57 \pm 2.51$ & $70.64 \pm 2.81$ & $86.34 \pm 4.79$ \\
\hline & PRWX & 0.00 & $8.73 \pm 0.14$ & $9.90 \pm 0.44$ & $24.31 \pm 0.59$ & $27.23 \pm 0.02$ \\
\hline \multirow[t]{3}{*}{ Bukalasa } & CTR & 0.00 & $25.50 \pm 4.39$ & $49.51 \pm 2.62$ & $71.81 \pm 9.91$ & $86.30 \pm 8.58$ \\
\hline & PR & 0.00 & $19.02 \pm 0.85$ & $30.15 \pm 3.25$ & $63.44 \pm 0.98$ & $67.39 \pm 17.95$ \\
\hline & PRWX & 0.00 & $8.11 \pm 0.42$ & $10.36 \pm 0.74$ & $15.09 \pm 2.41$ & $23.12 \pm 4.89$ \\
\hline $\operatorname{LSD}(0.05)$ & & 0.00 & 13.86 & 12.33 & 5.66 & 8.61 \\
\hline
\end{tabular}

consumption, much as the added advantage of PPD resistance is not exploited as they are not popular with farmers in the same way as the local varieties (Tumuhimbise et al., 2012).

Pruning reduced PPD values at 14 days of storage by more than $50 \%$ compared to the control. The average PPD at 14 days' storage for all the varieties was $22.9 \%$ for PR, compared to $40.72 \%$ for CTR. However, at 28 days' storage, the mean PPD for PR $(79.30 \%)$ was not significantly $(\mathrm{P}<0.05)$ different from that of the control $(87.41) \%$. The improved varieties, NASE 14 and TME 14, still exhibited a better performance (low PPD values) at all days compared to the local varieties. Thus, utilisation of improved varieties, is relevant for farmers that market the cassava roots and require pruning technology for shelf life improvement.

For all varieties, treatment PRWX had significantly lower PPD values than pruning alone during storage (Fig. 1). Values of PPD for PRWX ranged between $41 \%$ at 14 days storage and $18-27 \%$ at 28-day storage. With PRWX treatment, TME 14 had the lowest PPD (4.70\%); while Kirimumpale exhibited the highest PPD value (9.9\%) at 14 day's storage. At 28 day's storage, TME 14 had the least PPD of $18.29 \%$, and NASE 14 the highest $(28.55 \%)$. In all cases, the local varieties posted PPD values above $40 \%$ after 28 days, and were highly susceptible to PPD. The low PPD values in the improved varieties allude to the commercial value of these varieties. Their 


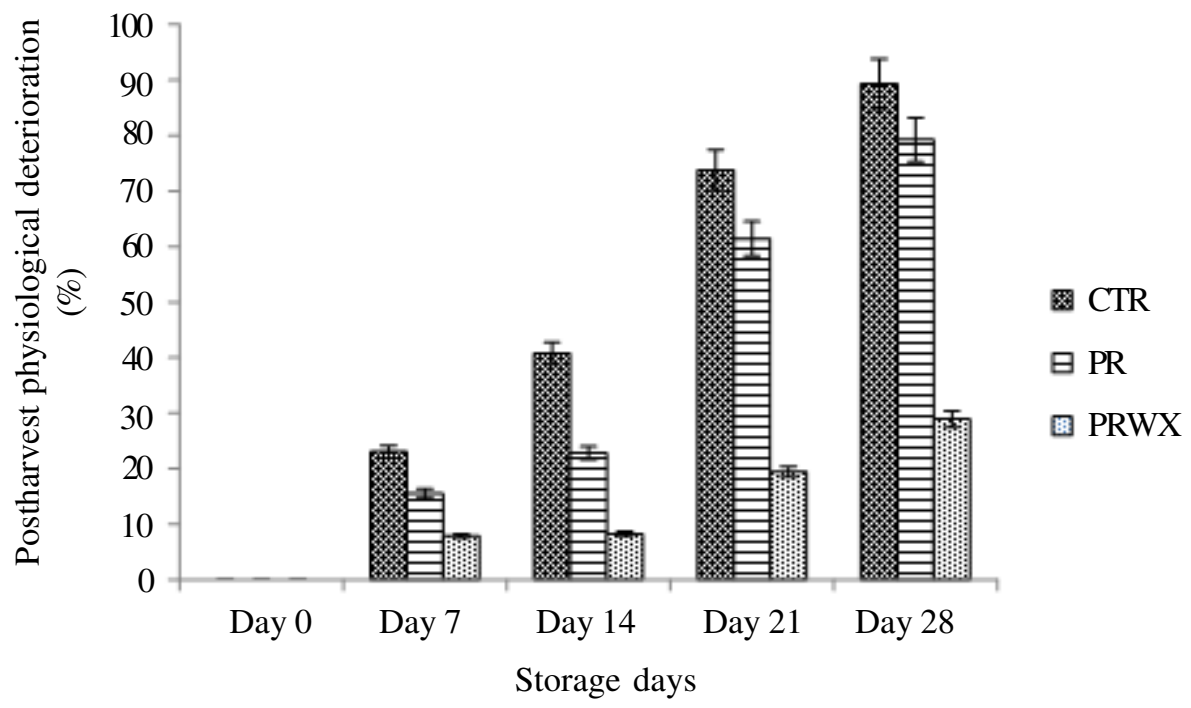

Figure 1. Effect of pruning of cassava plants and waxing of tubers on postharvest physiological deterioration $(\mathrm{PPD})$ of stored root tubers. $\mathrm{CTR}=$ Control roots, not pruned, $\mathrm{PR}=$ Pruned roots treatment, PRWX = Pruned and waxed roots treatment.

good response to the waxing technology also shows their relevance in the market and their ability to be marketed over extended periods after harvest and for upscale markets including the export market.

The low PPD values observed in the pruning treatment suggest that pruning plants before harvesting is important in slowing down the rate of physiological root deterioration. Such low PPD values give a strong reason for increasing the shelf life of roots from pruned plants further by waxing. These procedures were, thus implicated in slowing down the rate of root deterioration in comparison with situations where roots are marketed without any treatments. Thus, pruning and waxing of roots from plants presents a more reliable method of delaying PPD and extending shelf life. Further studies are required to assess the economic relevance of these technologies and their possible application at farm level.

Root dry matter content. In cassava, the dry matter content (DMC) describes the available solid mass of the cassava root (Table 2) and is an important parameter in the utilisation of cassava by consumers
(Montagnac et al., 2009). In this study, the DMC ranged from 31.4 to $36.2 \%$ across the test varieties, immediately after harvesting (Table 2). For the varieties studied, significant differences $(p<0.05)$ in dry matter content were observed. The two improved varieties (TME 14 and NASE 14) had higher dry matter contents (34.48 and $36.21 \%$ for untreated roots, respectively), compared with the local cultivars (31.41 - 32.73\%). Deliberate selection in the breeding programme for cassava in Uganda have aimed at varieties with high DMC for increased calorie production and, hence, food security (Kawuki et al., 2011). This explains the high DMC content observed for improved varieties. Also, treatment-based differences were observed for dry matter contents for different storage days $(\mathrm{P}<0.05)$. However, with storage, the dry matter increased to a range of $40.88-51.45 \%$ after 21 days of storage, and from 39.69 to $53.18 \%$ after 28 days of storage (Table 2). The increments point to loss in moisture of cassava during storage; and are indication that moisture loss may modulate root deterioration in cassava. 
TABLE 2. Changes in the dry matter content during storage of stored tubers of cassava plants pruned and waxed before storage in Uganda

\begin{tabular}{|c|c|c|c|c|c|c|}
\hline \multirow[t]{2}{*}{ Variety } & \multirow[t]{2}{*}{ Treatment } & \multicolumn{5}{|c|}{ Storage period (days) } \\
\hline & & 0 & 7 & 14 & 21 & 28 \\
\hline \multirow[t]{3}{*}{ TME 14} & CTR & $36.21 \pm 0.72$ & $45.72 \pm 2.11$ & $47.09 \pm 0.05$ & $51.45 \pm 1.10$ & $50.74 \pm 0.87$ \\
\hline & PR & $35.62 \pm 0.56$ & $44.76 \pm 3.97$ & $47.19 \pm 0.49$ & $50.27 \pm 0.25$ & $53.18 \pm 1.49$ \\
\hline & PRWX & $35.43 \pm 0.61$ & $42.27 \pm 5.40$ & $45.25 \pm 1.49$ & $44.45 \pm 0.83$ & $45.66 \pm 2.74$ \\
\hline \multirow[t]{3}{*}{ NASE 14} & CTR & $34.48 \pm 0.69$ & $42.29 \pm 0.98$ & $45.09 \pm 0.30$ & $49.15 \pm 0.54$ & $53.49 \pm 0.27$ \\
\hline & PR & $34.83 \pm 0.26$ & $42.74 \pm 0.13$ & $45.98 \pm 0.35$ & $49.87 \pm 0.11$ & $53.09 \pm 0.91$ \\
\hline & PRWX & $34.07 \pm 0.28$ & $39.32 \pm 2.09$ & $43.69 \pm 1.86$ & $42.59 \pm 1.22$ & $47.97 \pm 0.47$ \\
\hline \multirow[t]{3}{*}{ Nyaraboke } & CTR & $32.73 \pm 0.03$ & $36.44 \pm 0.83$ & $39.37 \pm 1.65$ & $44.21 \pm 1.44$ & $42.12 \pm 3.11$ \\
\hline & PR & $31.77 \pm 0.43$ & $38.35 \pm 0.57$ & $41.37 \pm 1.40$ & $44.82 \pm 0.08$ & $45.09 \pm 0.20$ \\
\hline & PRWX & $31.48 \pm 0.59$ & $35.73 \pm 1.52$ & $38.72 \pm 1.73$ & $40.88 \pm 0.70$ & $39.69 \pm 1.68$ \\
\hline \multirow[t]{3}{*}{ Kirimumpale } & CTR & $31.41 \pm 0.67$ & $41.52 \pm 0.74$ & $41.82 \pm 1.39$ & $45.72 \pm 0.53$ & $46.87 \pm 1.37$ \\
\hline & PR & $31.53 \pm 0.20$ & $42.01 \pm 0.09$ & $42.42 \pm 0.86$ & $45.49 \pm 1.19$ & $47.26 \pm 0.69$ \\
\hline & PRWX & $31.53 \pm 0.69$ & $36.72 \pm 1.25$ & $39.07 \pm 0.95$ & $42.47 \pm 1.58$ & $40.69 \pm 2.11$ \\
\hline \multirow[t]{3}{*}{ Bukalasa } & CTR & $32.55 \pm 0.65$ & $39.12 \pm 0.73$ & $41.74 \pm 2.45$ & $44.36 \pm 1.81$ & $43.42 \pm 7.24$ \\
\hline & PR & $32.68 \pm 0.35$ & $42.32 \pm 0.74$ & $43.18 \pm 0.52$ & $46.86 \pm 0.04$ & $48.00 \pm 0.03$ \\
\hline & PRWX & $32.61 \pm 0.10$ & $42.95 \pm 0.06$ & $41.32 \pm 2.52$ & $43.66 \pm 1.44$ & $43.40 \pm 0.15$ \\
\hline LSDs (0.05) & & 0.66 & 3.31 & 1.03 & 2.67 & 2.66 \\
\hline
\end{tabular}

CTR = Control roots, not pruned; PR = Pruned roots treatment; PRWX = Pruned and waxed roots treatment

In this study, the increments in dry matter were higher among CTR and PR samples compared to PRWX (Table 2). Increments in dry matter contents, therefore, are directly linked with moisture loss during the deterioration process. Thus, the role of waxing in improving the shelf life of cassava is the regulation of moisture loss from the roots and hence, prevention of drying as was observed by Maltini et al. (2003).

In general, the increase in DMC during storage for the PRWX treatment, was less than for CTR or PR (Table 2). At day 14 after treatment, DMC content had increased by an average $8 \%$ in all varieties, and by mean $11 \%$ at 28 days after treatment for the PRWX treatment. On the other hand, the DMC content of the pruned roots increased by an average 10 and $16 \%$ for day 14 and day 28 respectively. In comparison, DMC increased by an average of 9 and $15 \%$ at day 14 and day 28 respectively in the control. The low rate of dry matter increase in PRWX could be important in delaying the onset of PPD in cassava. Thus, processes such as waxing, which maintain the moisture content of cassava roots may reduce the adverse effects of secondary metabolism associated with postharvest physiological deterioration plant tissues (Maltini et al., 2003; Zidenga et al., 2012). 
Starch yield. Results for the test varieties indicated significantly $(\mathrm{P}<0.05)$ higher starch yield in improved varieties compared to the local varieties (Table 3 ). Starch yield ranged between 20 and $22 \%$ in local varieties of Nyaraboke, Kirimumpale and Bukalasa compared to $22-26 \%$ in the improved varieties. Such differences affect the utilisation of cassava in different application, with low starch yield varieties being popular with farmers and for fresh consumption (Nuwamanya et al., 2010). TME 14 had the highest starch yield (25.31\%); while Kirimumpale had the lowest (20.30\%). However, pruned samples for TME 14 and Nyaraboke had lower starch yields than their corresponding unpruned roots at day 0 . Pruned samples of NASE 14, Kirimumpale and
Bukalasa exhibited higher starch yields than their corresponding unpruned roots, though the differences were not significant $(\mathrm{P}>0.05)$ (Table 3).

These results partly indicate that the effects of pruning are variety specific and, therefore, selection of varieties with better response to pruning is possible. For all the varieties tested, starch yields reduced in all samples from a range of $20.76-25.31 \%$ at day 0 to $12.15-$ $18.48 \%$, at day 14 and $10.41-16.49 \%$ at day 28; representing $30-45 \%$ loss after 28 days of storage. In all cases, except at day 0 , differences in reduction in starch yield were observed due to the treatment of the different varieties and different storage times (Table 3). Loss of starch on pruning of the root is indicative of starch remobilisation to support

TABLE 3. Changes in starch yield of the selected cassava varieties over experimental time

\begin{tabular}{|c|c|c|c|c|c|c|}
\hline \multirow[t]{2}{*}{ Variety } & \multirow[t]{2}{*}{ Treatment } & \multicolumn{5}{|c|}{ Storage period (days) } \\
\hline & & 0 & 7 & 14 & 21 & 28 \\
\hline \multirow[t]{3}{*}{ TME 14} & CTR & $25.31 \pm 1.59$ & $19.49 \pm 0.41$ & $15.62 \pm 0.60$ & $16.63 \pm 1.08$ & $14.14 \pm 0.95$ \\
\hline & PR & $23.76 \pm 1.25$ & $20.26 \pm 0.21$ & $17.65 \pm 0.09$ & $14.82 \pm 0.19$ & $13.77 \pm 0.01$ \\
\hline & PRWX & $22.80 \pm 1.54$ & $20.04 \pm 0.04$ & $18.48 \pm 0.61$ & $18.02 \pm 0.06$ & $17.32 \pm 0.53$ \\
\hline \multirow[t]{3}{*}{ NASE 14} & CTR & $22.00 \pm 1.03$ & $19.09 \pm 0.04$ & $17.28 \pm 0.05$ & $16.18 \pm 0.13$ & $16.49 \pm 0.71$ \\
\hline & PR & $23.73 \pm 0.40$ & $20.11 \pm 0.05$ & $16.71 \pm 0.04$ & $15.68 \pm 0.04$ & $14.32 \pm 0.00$ \\
\hline & PRWX & $20.76 \pm 1.27$ & $19.85 \pm 0.93$ & $18.17 \pm 0.86$ & $17.72 \pm 0.09$ & $17.54 \pm 0.01$ \\
\hline \multirow[t]{3}{*}{ Nyaraboke } & CTR & $22.69 \pm 1.51$ & $16.28 \pm 0.21$ & $15.17 \pm 0.08$ & $14.30 \pm 0.16$ & $14.28 \pm 0.76$ \\
\hline & PR & $21.29 \pm 2.16$ & $17.45 \pm 0.37$ & $15.12 \pm 0.09$ & $15.09 \pm 0.01$ & $12.77 \pm 0.62$ \\
\hline & PRWX & $20.83 \pm 1.43$ & $17.32 \pm 0.18$ & $16.79 \pm 0.22$ & $16.11 \pm 0.40$ & $15.10 \pm 1.29$ \\
\hline \multirow[t]{3}{*}{ Kirimumpale } & CTR & $20.30 \pm 1.09$ & $16.03 \pm 1.26$ & $14.45 \pm 0.40$ & $13.60 \pm 0.40$ & $13.24 \pm 0.04$ \\
\hline & PR & $21.55 \pm 0.46$ & $18.29 \pm 1.48$ & $15.77 \pm 0.08$ & $14.39 \pm 0.31$ & $11.29 \pm 0.24$ \\
\hline & PRWX & $21.48 \pm 2.52$ & $17.44 \pm 1.80$ & $16.66 \pm 0.74$ & $16.97 \pm 0.59$ & $15.96 \pm 0.24$ \\
\hline \multirow[t]{3}{*}{ Bukalasa } & CTR & $23.81 \pm 1.48$ & $15.02 \pm 0.00$ & $12.15 \pm 0.06$ & $13.24 \pm 0.04$ & $11.06 \pm 1.15$ \\
\hline & PR & $24.84 \pm 0.11$ & $18.02 \pm 0.00$ & $13.72 \pm 0.06$ & $13.67 \pm 0.27$ & $10.41 \pm 1.09$ \\
\hline & PRWX & $21.49 \pm 0.06$ & $16.41 \pm 0.00$ & $13.43 \pm 0.05$ & $13.39 \pm 0.06$ & $12.87 \pm 0.01$ \\
\hline $\operatorname{LSD}(0.05)$ & & 2.02 & 0.92 & 1.19 & 1.62 & 1.23 \\
\hline
\end{tabular}

CTR $=$ Control roots, not pruned; $\mathrm{PR}=$ Pruned roots treatment; PRWX $=$ Pruned and waxed roots treatment 
recurrent growth (Nuwamanya et al., 2014). However, the mechanisms of such losses in cassava have not been elucidated, much as they are linked to increase in amylase activity within the root leading to starch remobilisation (Critchley et al., 2001)

Reduction of root starch yield during storage was higher for CTR than for PR and PRWX. For CTR, starch yield was reduced by $34.6 \%$ at day 14 and by $39.8 \%$ at day 28 . The corresponding reductions for PR were 31.4 at day 14 and $40.1 \%$ at day 28 ; reductions for PRWX were $22.1 \%$ at day 14 and $26.5 \%$ at day 28. Lower reductions for starch yield during storage was, therefore, exhibited by PRWX treatment.

The results indicate that PPD results into loss of starch and the caloric value of cassava, especially if the cassava is to be used for consumption. Such losses include the degradation of starch during PPD, and the utilisation of carbohydrates as energy sources for offsetting the effects of stress on the root tissue as a result of PPD (Zidenga et al., 2012).

The losses reduce the economic value of the roots, making them unmarketable (Saravan et al., 2016). The maintenance of high starch yields in the waxed treatment is, therefore, an important indicator of the role of waxing in delivering quality cassava to the market, and therefore, represents reduction in quality losses of fresh cassava (Affognon et al., 2015).

Root reducing sugars. Significant differences were observed among treatments for changes in reducing contents of the root during storage (Fig. 2). Higher increments in reducing sugars were observed in the control (CTR) samples, compared with the pruned and waxed treatment. Initial reducing sugar contents ranged from mean of $1.2-2.4 \%$ of the whole root mass among the different varieties, showing varietal differences in accumulation of reducing sugars within the root. The reducing sugar content, however, increased to mean of $6.9-8.3 \%$ by day 7 and was an average of $11-17 \%$ after day 28 . Reducing sugar contents at day 28 was $17.18 \%$ for CTR, $14.85 \%$ for PR, and $10.73 \%$ for PRWX. The increments were in tandem with increasing PPD score in the control and pruned treatments; an indication of the breakdown of starch into simple sugars in the root.

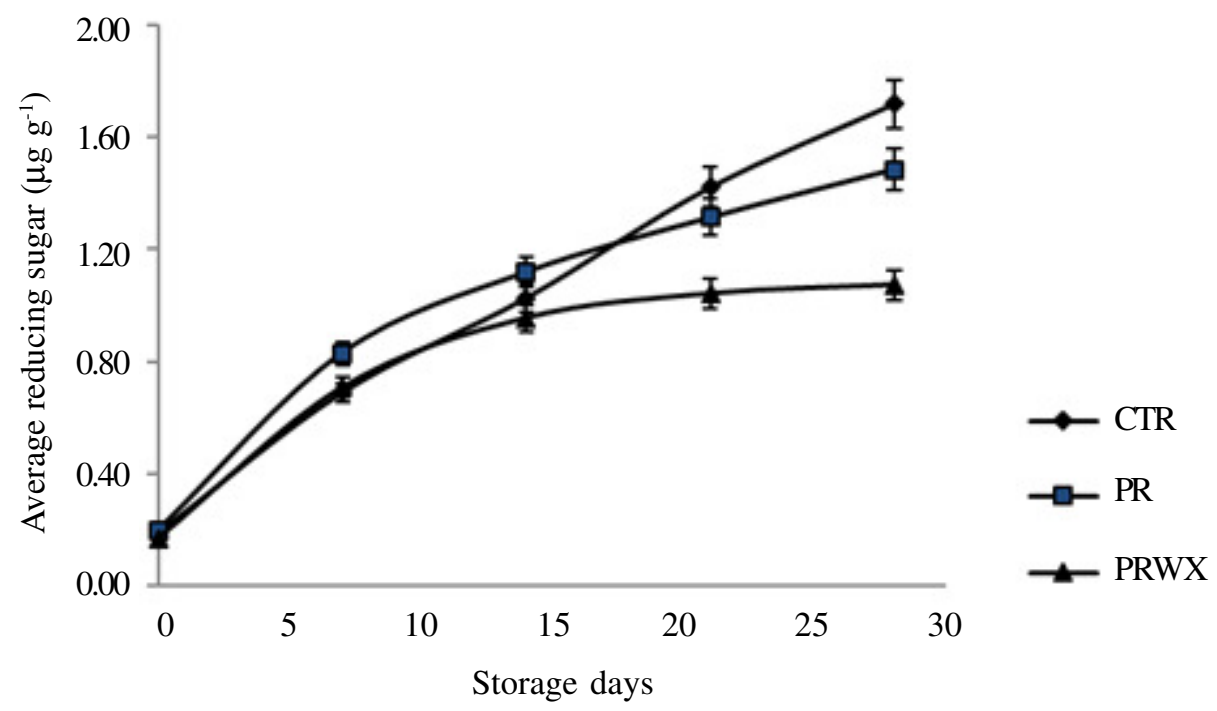

Figure 2. Change in reducing sugar content of cassava roots under different treatments in Uganda. CTR = Control roots, not pruned; PR = Pruned roots treatment; PRWX = Pruned and waxed roots treatment. 
The high values observed clearly show that PPD results into degradation of carbohydrates, as was observed by Zidenga et al. (2012). The lower values of reducing sugars in PRWX suggest a lower rate of physiological deterioration after waxing. The results also justify the role of waxing as an important method of preservation of root quality during storage in cassava (Saravan et al., 2016).

No significant differences were observed in reducing sugars among the individual varieties at the specified sampling times (Fig. 2). The increase in reducing sugars observed is due to the breakdown of carbohydrates, especially starch (Nuwamanya et al., 2014). This phenomenon can be attributed to carbohydrate based metabolism that leads to production of PPD related stress modulating defense responses (metabolites) against physiological deterioration (Zidenga et al., 2012). The similarities observed among varieties for increments in reducing sugars point to the influence of the processing environment on the degradation processes of carbohydrates during PPD (Zidenga et al., 2012).

Root cyanide content. All the varieties tested in this study had cyanide contents in the fresh roots ranging from 34.5 to $76.6 \mathrm{ppm}$ (Fig. 3). Such varieties are classified as sweet varieties and relate to most of the farmer preferred and improved varieties used in Uganda (Kawuki $e t$ al., 2013). Variety TME 14 had the highest cyanide content (76.6 ppm); while variety Nyaraboke had lowest cyanide content (15.7 ppm) before treatment.

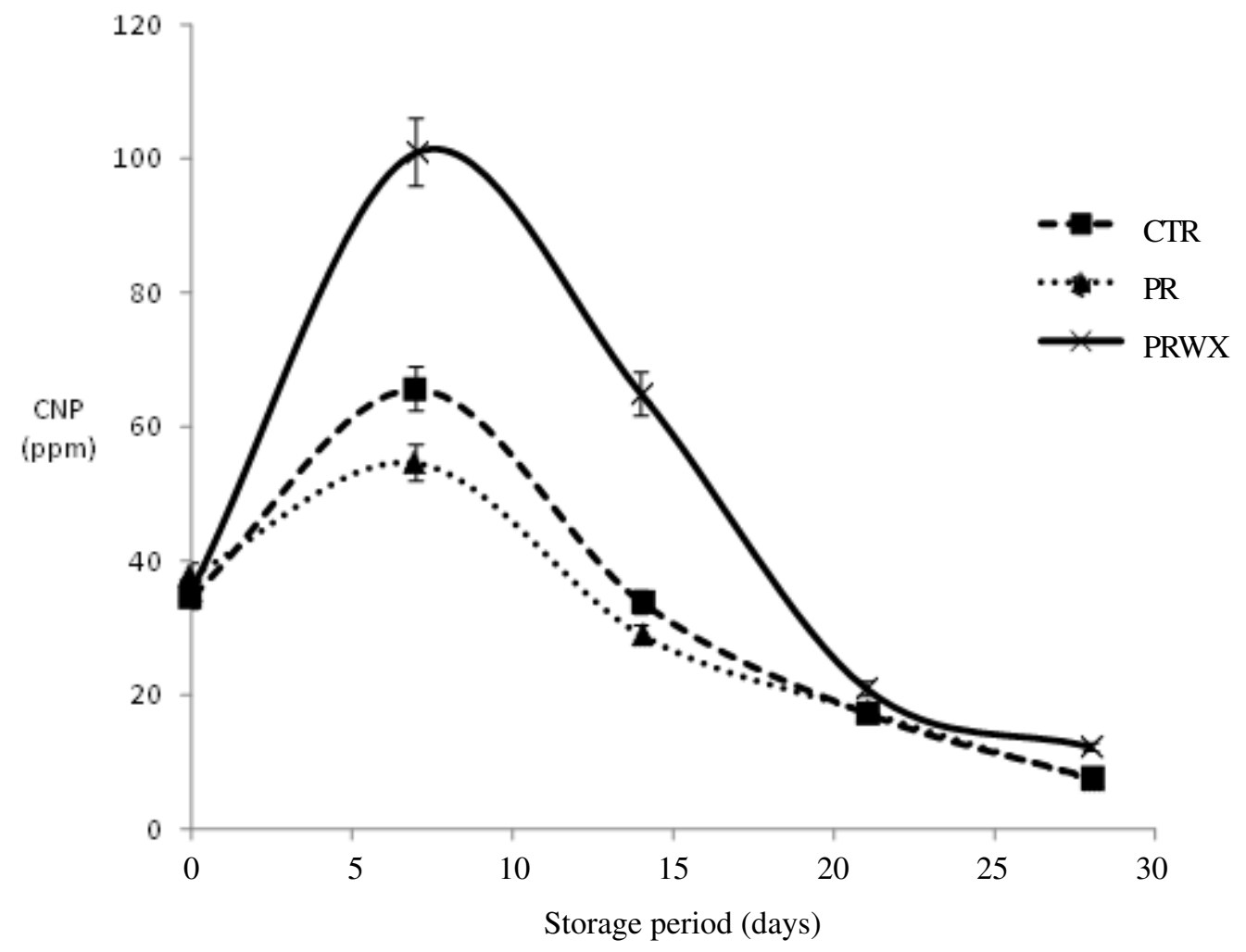

Figure 3. Changes in the cyanogenic potentials (CNP; ppm) of cassava roots during storage and under different treatments in Uganda. CTR $=$ Control roots, not pruned; PR = Pruned roots treatment; $\mathrm{PRWX}=$ Pruned and waxed roots treatment. 
Significant differences $(\mathrm{P}<0.05)$ observed in cassava varieties for cyanogenic content, indicate the possibility of selecting specific varieties for postharvest treatment and extended storage or immediate consumption. Storage of these varieties resulted in initial increments in the cyanide content; followed by a consistent reductions regardless of the treatment. Reductions of up to $80 \%$ were observed, reaching to as low as $14 \%$ in TME 14 and about $10 \%$ in local varieties Kirimumpale and Nyaraboke. The initial increase in cyanide observed (Fig. 3) was related to loss of moisture, which results into increased conversion of bound cyanide to volatile cyanide as linamarase activity increases (Kojima et al., 1983). In particular, pruning (PR) resulted into decrease in the cyanogenic content, ranging between $20-50 \mathrm{ppm}$ in different varieties after harvest (Fig. 3); with progressive reductions observed as storage time increased. In addition, the PRWX treatment resulted in reduction in cyanide, ranging from $28.95 \mathrm{ppm}$ to $64.87 \mathrm{ppm}$ with higher reductions observed in the variety TME 14.

Reductions in cyanide content of the control samples followed a similar trend and ranged between 17.3 and 20.95 ppm (Fig. 3); showing that storage of cassava tubers before utilisation, increases the cyanide related concerns safety of the roots for consumption, as suggested Montagnac et al. (2009). However, the reductions observed could be appropriate for varieties with low cyanogenic potential, and thus related pre-processing and processing procedures for reduction of cyanide are still required (Cardoso et al., 2005), even with the waxing and pruning treatments. The physiological basis of such reductions after long term storage are related to the breakdown of $\mathrm{HCN}$ in volatile cyanide as alluded to by Montagnac et al. (2009).

Exposure of the roots results into loss of the volatile cyanide, much as such exposure increases the physiological deterioration of the root. Given the role of hydrogen cyanide as a stress related secondary metabolite (Nyirenda et al., 2012), it is important to note that losses in cyanide will increase the propensity of the root to deteriorate. Thus, minimal reductions in cyanide during storage would be desired for improved shelf life. However, this is not ideal given the serious safety and health impacts of cyanide on consumers. Such safety and health impacts have implications on cassava product safety and calls for implementation of safety strategies in marketing of fresh cassava products.

Amylose content. The amylose content of starch extracted from fresh cassava roots used in this study was on average $15 \%$, and with no significant differences $(\mathrm{P}>0.05)$ observed among the varieties used, as differences were observed between the different treatments (Fig. 4). The improved varieties, NASE 14 and TME 14, exhibited higher values even after different storage treatment regimes. However, significant differences $(\mathrm{P}>0.05)$ were observed between the pruned (PR) and the unpruned roots (CTR); with higher amylose contents observed in starch from pruned plants (15-19\%) compared to the control (15$17 \%)$.

The high amylose content in the pruned roots can be attributed to carbohydrate based physiological breakdown related to increased amylase activity, as the plant prepares to remobilise sugars for growth after sprouting (Zidenga et al., 2012). During storage, the amylose content initially increased in all treatments, and at day 7 it ranged from 15.2 to $16.9 \%$ on average representing an increase of $3.6-6.4 \%$ for the different varieties in the different treatments (Fig. 4).

Higher amylose content was observed for all treatments, with CTR (16.21\%) having slightly higher contents compared to PR (16.09\%) and PRWX treatments (16.18) at day 7. This increment in amylose realised could be attributed to the increase in starch hydrolysis in the stored roots, resulting into breakdown of the amylopectin fraction of the 


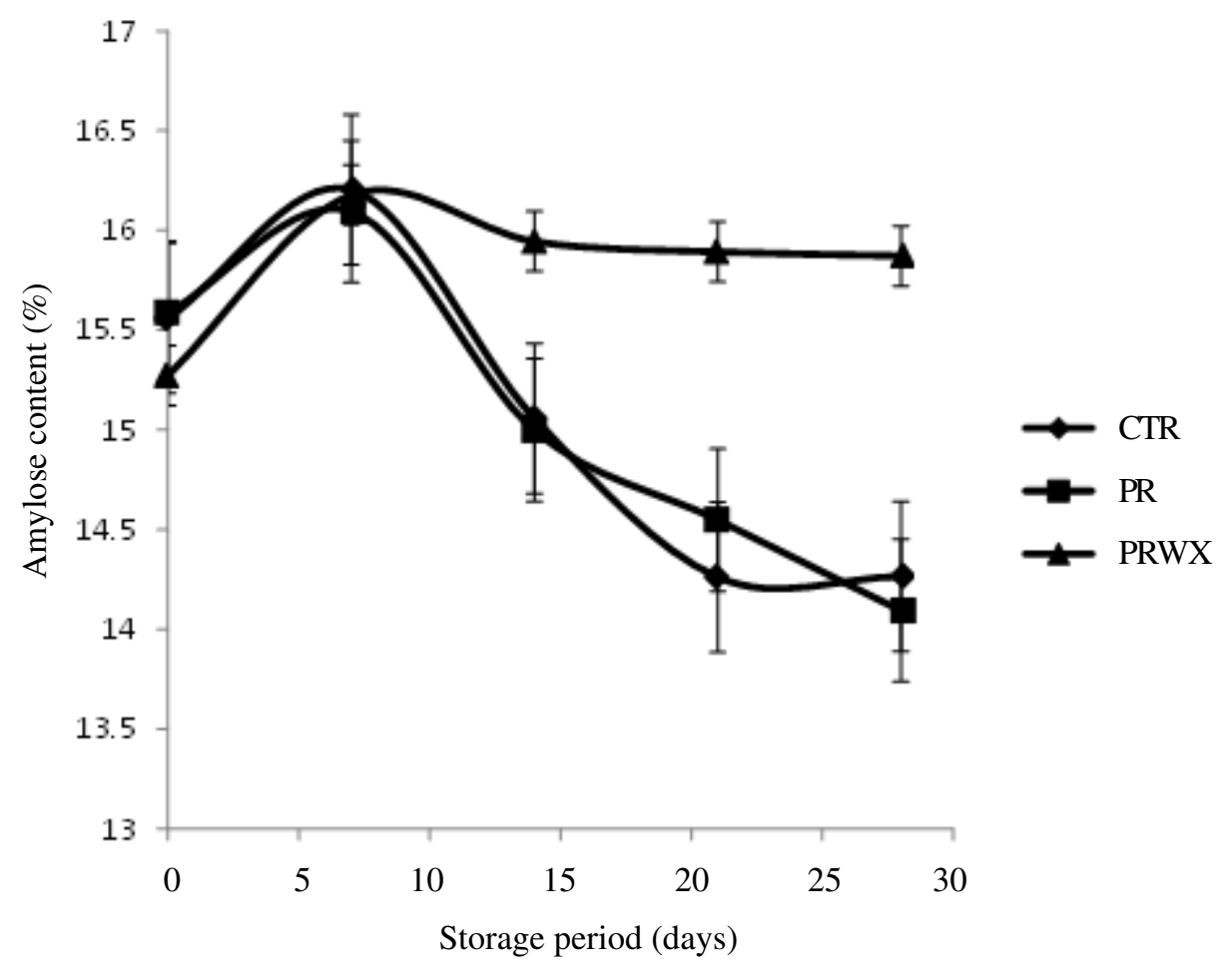

Figure 4. Changes in amylose content of extracted starch across treatments and varieties. CTR = Control roots, not pruned; PR = Pruned roots treatment; PRWX = Pruned and waxed roots treatment.

starch, as suggested by Zeeman et al. (2010). Pruning and waxing of the roots therefore reduces the effect of processing environment on amylase mediated metabolism of the root. This henceforth reduces the rate of amylopectin breakdown into linear amylose chains. Zidenga et al. (2012) reported specific physiologically mediated breakdown of starch leading to production of short chain carbohydrates (amylose and its components), which in essence reduces the quality of the root. Reduction in amylose content was, however, observed in CTR (15.06\%) and PR (14.99\%) after 14 days; while no significant reductions were observed for amylose content in the PRWX treatment. Further reductions were observed with amylose content below $13.5 \%$ in both the PR and CTR samples by 28 days. However, no significant reductions were observed for the PRWX treatment with maintenance of amylose content above 15\% during storage (Fig. 4).
The progressive reductions in PR and CTR can be attributed to the negative effects of PPD on total root carbohydrates as earlier suggested by van Oischort et al. (2016). In addition, these reductions confirm the role of starch in mediating PPD where high starch contents have been implicated in increased physiological damage during PPD. The results, therefore, show that PPD affects the carbohydrate quality of the root. Such effects can be offset by waxing of the roots which improves stored root quality.

Relationship between PPD and root components. At 28 days, a significant positive correlation was observed between PPD and dry matter content $(r=0.645)$ for the control and pruned samples. This was an indicator that reduction in root moisture leading to temporal increment in dry matter content increases stress disposition, hence, the possibility of spoilage of the root. However, 
the relationship was not significant for PRWX treatment, explaining the maintenance of dry matter once the PPD is reduced. The relationship explains the role of alternative oxidase (AOX gene) in uncoupling carbon metabolism from ATP generation during physiological deterioration (Zidenga et al., 2012).

Positive and significant correlations existed between cyanide and starch yield $(r=0.622)$, and starch content $(r=0.581)$, which are both elements of dry matter. This may be related to the role of cyanogenesis in delaying the onset and progression of PPD, by inhibiting root based respiratory processes. Such processes reduce the carbohydrate content and further increase the effects PPD on the root as suggested by Kizito et al. (2005) and Zidenga et al. (2012). Dry matter content was negatively correlated with starch content $(\mathrm{r}=$ $-0.502)$, but positively correlated with PPD $(r=0.506)$, which shows the reduction in starch content (a major component of dry matter in cassava) due to PPD.

Amylose content was positively correlated to cyanide (0.615), but negatively correlated to PPD (-0.892). Negative but weak correlations between starch content and reducing sugars $(-0.371)$ were also observed, an indication that accumulation of sugars is a result of hydrolysis of starch in the root as the root undergoes deterioration stress.

\section{ACKNOWLEDGEMENT}

This work was funded by the European Commission (EC) in the Roots, Tubers and Bananas project "Expanding Utilisation of RTB and reducing their postharvest losses" (RTBENDURE) Grant Number 2000000488 led by the Consultative Group on International Agricultural Research (CGIAR). We appreciate the effort of Dr. Dominique Dufour for organizing the cross-learning visit to CIAT, Colombia. The Food and Biosciences Programme at NARL and the cassava programme at NACRRI for providing the technical and administrative support for this work.

\section{REFERENCES}

Abass, A.B., Ndunguru, G., Mamiro, P., Alenkhe, B., Mlingi, N. and Bekunda, M. 2014. Post-harvest food losses in a maizebased farming system of semi-arid savannah area of Tanzania. Journal of Stored Products Research (57):49-57.

Affognon, H., Mutungi, C., Sanginga, P. and Borgemeister, C. 2015. Unpacking postharvest losses in Sub-Saharan Africa: A meta-analysis. World Development (66):49-68.

American Association of Cereal Chemists International. 2000. Approved Methods of Analysis, 11th Ed. AACCI 360 Method 4611.02. Crude Protein - Improved Kjeldahl Method, Copper Catalyst Modification. AACC 361 International, St. Paul, MN, U.S.A. 362pp.

Association of Official Analytical Chemists (AOAC). 2002. Official Methods of Analysis. 15th ed. Association of Official Analytical Chemists, Arlington, VA.

Asaoka, M., Blanshard, J.M.V. and Rickard, J,E. 1993. The effect of pre-harvest pruning on the quality of cassava starch. Annals of Applied Biology 122:337-344

Atanda, S.A., Pessu, P.O., Agoda, S., Isong, I.U. and Ikotun, I. 2011. The concepts and problems of post-harvest food losses in perishable crops. African Journal of Food Science 5(11):603-613,

Benesi, I.R.M., Labuschagne, M.T., Herselman, L., Mahungu, N.M. and Saka, J.K. 2008. The effect of genotype, location and season on cassava starch extraction. Euphytica 160(1):59-74.

Bhat, R., Alias, A. K. and Paliyath, G. 2012. Use of electron beams in food preservation. Progress in food preservation. 343pp.

Bradbury, J.H., Egan, S.V. and Lynch, M.J. 1991. Analysis of cyanide in cassava using acid hydrolysis of cyanogenic glucosides. 
Journal of the Science of Food and Agriculture 55:277-290.

Cardoso, A.P., Mirione, E., Ernesto, M., Massaza, F., Cliff, J., Haque, M.R. and Bradbury, J.H. 2005. Processing of cassava roots to remove cyanogens. Journal of Food Composition and Analysis 18(5):451-460.

Critchley, J.H., Zeeman, S.C., Takaha, T., Smith, A.M. and Smith, S.M. 2001. A critical role for disproportionating enzyme in starch breakdown is revealed by a knock out mutation in Arabidopsis. The Plant Journal 26(1):89-100.

Ezeocha, V.C. and Oti, E. 2013. Effects of waxing materials and storage periods on physico- chemical properties of trifoliate yam (Dioscorea dumetorum). Applied Science Report 4(2):219-224

Kawuki, R.S., Pariyo, A., Amuge, T., Nuwamanya, E., Ssemakula, G., Tumwesigye, S., Bua, A., Baguma, Y., Omongo, C., Alicai, T. and Orone, J. 2011. A breeding scheme for local adoption of cassava (Manihot esculenta Crantz). Journal of Plant Breeding and Crop Science 3(7):120-130.

Kawuki, R.S., Herselman, L., Labuschagne, M.T., Nzuki, I., Ralimanana, I., Bidiaka, M., Kanyange, M.C., Gashaka, G., Masumba, E., Mkamilo, G. and Gethi, J. 2013. Genetic diversity of cassava (Manihot esculenta Crantz) landraces and cultivars from southern, eastern and central Africa. Plant Genetic Resources 11(2):170181.

Kawuki, R.S., Kaweesi, T., Esuma, W., Pariyo, A., Kayondo, I.S., Ozimati, A. Nuwamanya E. and Baguma, Y. 2016. Eleven years of breeding efforts to combat cassava brown streak disease. Breeding Science 66(4):560-571. http://doi.org/ 10.1270/jsbbs. 16005

Kizito, E., Bua, A., Fregene, M., Egwang, T., Gullberg, U. and Westerberg, A. 2005. The effect of cassava mosaic disease on the genetic diversity of cassava in Uganda. Euphytica 146:45-54.

Maltini, E., Torreggiani, D., Venir, E. and Bertolo, G. 2003. Water activity and the preservation of plant foods. Food Chemistry 82(1):79-86.

Morante, N., Sanchez, T., Ceballos, H., Calle, F., Perez, J.C., Egesi, C., Cuambe, C,F., Escobar, D., Ortiz, D., and Chavez, A.L. 2010. Tolerance to postharvest physiological deterioration in cassava roots. Crop Science 50:1333-1338

Montagnac, J.A., Davis, C.R. and Tanumihardjo, S.A. 2009. Nutritional value of cassava for use as a staple food and recent advances for improvement. Comprehensive Reviews in Food Science and Food Safety 8(3):181-194.

Nassar, N. and Ortiz, R. 2010. Breeding cassava to feed the poor. Scientific American 302(5):78-85.

Nuwamanya, E., Rubaihayo, P.R., Mukasa, S., Kyamanywa, S., Hawumba, J.F. and Baguma, Y. 2014. Biochemical and secondary metabolites changes under moisture and temperature stress in cassava (Manihot esculenta Crantz). African Journal of Biotechnology 13(31).

Nyirendah, D.B., Afoakwa, E.O., Asiedu, C., Budu, A.S. and Chiwona-Karltun, L. 2012. Chemical composition and cyanogenic potential of traditional and high yielding CMD resistant cassava (Manihot esculenta Crantz) varieties. International Food Research Journal 19(1):175-181.

Sánchez, T., Dufour, D., Moreno, J.L., Pizarro, M., Aragón, I.J. and Domínguez, M. 2013. Changes in extended shelf life of cassava roots during storage in ambient conditions. Postharvest Biology and Technology 86:520-528.

Saravanan, R., Ravi, V., Stephen, R., Thajudhin, S. and George, J. 2016. Postharvest Physiological Deterioration of Cassava (Manihot esculenta)-A review. Indian Journal of Agricultural Sciences 86(11):1383-1390. 
Simonyan, K.J. 2014. Cassava post-harvest processing and storage in Nigeria: A review. African Journal of Agricultural Research, 9(53), 3853-3863.

Tumuhimbise, R., Shanahan, P., Melis, R. and Kawuki, R. 2014. Combining ability analysis of storage root yield and related traits in cassava at the seedling evaluation stage of breeding. Journal of Crop Improvement 28(4):530-546.

Tumuhimbise, R., Melis, R., Shanahan, P. and Kawuki, R. 2012. Farmers' perceptions on early storage root bulking in cassava (Manihot esculenta Crantz) in east and central Uganda and their implication for cassava breeding. World Journal of Agricultural Sciences 8(4):403-408.

Van Oirschot, Q.E.A., O’Brien, G.M., Dufour, D., El Sharkawy M.A. and Mesa E. 2000. The effect of pre-harvest pruning of cassava upon root deterioration and quality characteristics, Journal of the Science of Food and Agriculture 80(13):1866-1873.

Wanda, K., Okello, G., Menya, G., Businge, A., Byaruhanga, Y., Mlingi, N. and Abass, A. 2014. Extending the shelf life of fresh cassava roots for increased incomes and postharvest losses reduction in Uganda: A proposed business case. Poster prepared for the RTB Annual Meeting in Entebbe, Uganda, 29 Sep-3 Oct 2014, http:// www.rtb.cgiar.org/wp- Cassava Shelflife. pdf

Wenham J.E. 1995. Post-harvest deterioration of cassava: A biotechnology perspective. Plant Production and Protection Paper FAO No 130. FAO Plant Production and Protection, Rome, Italy.

Wheatley, C., Lozano, C. and Gómez, G. 1985. Post-harvest deterioration of cassava roots. In: Cock, JH.; Reyes, J.A. (Ed.). Cassava: research, production and utilization. Cali: UNDP CIAT, 1985. pp. 655-671.

Zeeman, S.C., Kossmann, J. and Smith, A.M. 2010. Starch: Its metabolism, evolution, and biotechnological modification in plants. Annual Review of Plant Biology 61:209234.

Zidenga. T., Leyva-Guerrero, E., Moon, H., Siritunga, D. and Sayre, R. 2012. Extending cassava root shelf life via reduction of reactive oxygen species production. Plant Physiology 159(4): 1396-1407. 